\title{
Cystoid foveal oedema in symptomatic inner lamellar macular holes
}

\begin{abstract}
Purpose Inner lamellar macular hole (LMH) was considered a relatively risk-free condition that rarely progresses or worsens. Nowadays, at the optical coherence tomography (OCT) era, increasing evidence seems to position it differently. The aim of the study was to describe morphologic abnormalities associated with symptomatic LMH using OCT that may explain reduced visual acuity in these patients. Methods In a retrospective study on consecutive symptomatic patients with LMH, OCT scans were compared with normal controls. Analysis was referred to LMH-associated abnormalities at the residual fovea, mainly cystoid spaces that manifested as cystoid foveal oedema.

Results A total of 22 eyes of 20 patients (mean age, 68 years; range, 22-94) were included in the study. Best-corrected visual acuity ranged from 6/9 to 6/120. Cystoid foveal oedema that contained cystoid spaces of various sizes was found in 21 (95\%) of eyes; an intraretinal split was seen in 18 eyes $(82 \%)$ and epiretinal membrane was detected in 16 eyes (73\%). Conclusions The appearance of cystoid oedema at the residual fovea in symptomatic LMHs may explain in part a reduced visual acuity and/or metamorphopsia. The old notion on the low incidence of LMH progression may probably be related in part to (a) lower diagnostic accuracy before OCT was available and to (b) the already spontaneously peeled inner limiting membrane. Further studies are required to verify these observations, which may merit clinical and surgical considerations. Eye (2009) 23, 1781-1785; doi:10.1038/eye.2008.369; published online 19 December 2008
\end{abstract}

Keywords: inner lamellar macular hole; optical coherence tomography; cystoid foveal oedema
A Ophir ${ }^{1,2}$ and S Fatum ${ }^{1}$

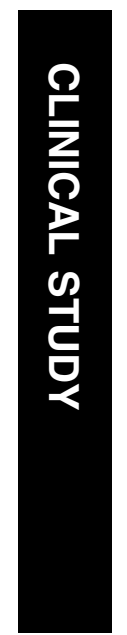

The cause of an inner lamellar macular hole (LMH) production, as described by Gass, ${ }^{1,2}$ was referred to as unroofing of a cyst in chronic cystoid macular oedema (CME), or to an abortive process of idiopathic macular hole formation. At that time, before the optical coherence tomography (OCT) era, minute morphologic abnormalities at the residual foveal tissue in LMH could not be accurately detected. Most patients with LMH seemed to retain good stable central vision, typically reported to range from $20 / 20$ to $20 / 80$, with or without metamorphopsia. ${ }^{3}$ Surgical

intervention was generally not indicated as the progression of LMH was considered rare.

Recently, high-resolution imaging techniques, mainly OCT, were found useful in the visualization of retinal anatomy with near microscopic resolution, ${ }^{4-10}$ and new data have been found regarding LMH: (a) best-corrected visual acuity (BCVA) as low as 20/200, 20/400 and counting fingers at 8 feet was reported in eyes with LMHs, ${ }^{, 1-13}$ (b) several studies showed persistent vitreous adherence to the edge of the $\mathrm{LMH}$, baring a potential for traction and LMH progression; ${ }^{13-15}$ (c) two reports showed an LMH in each that underwent spontaneous transition to a full-thickness macular hole, ${ }^{9,13}$ and (d) pars plana vitrectomy (PPV) and gas tamponade for symptomatic LMH improved visual acuity in most eyes, provided that it included peeling of the internal limiting membrane (ILM). ${ }^{11-13}$ All of the above seem to give rise to a revised concern about LMHs in regards to their morphologic abnormalities, natural history, potential of worsening, and the possibility of beneficial surgery with reversibility of symptoms.

In this study, the OCT appearance of symptomatic LMHs was evaluated, looking for morphologic abnormalities that could be
${ }^{1}$ Division of Ophthalmology, Hillel-Yaffe Medical Centre, Hadera, Israel

${ }^{2}$ The Technion, The Ruth and Bruce Rappaport Faculty of Medicine, Haifa, Israel

Correspondence: A Ophir, Division of Ophthalmology, Hillel-Yaffe Medical Centre, PO Box 169,

Hadera 38100, Israel

Tel: + 972547222688 ; Fax: + 97235409222 .

E-mail: ophthalmology@ hy.health.gov.il

Received: 27 May 2008 Accepted in revised form: 18 November 2008 Published online: 19 December 2008

Financial/proprietary interest: None 
associated with relatively poor visual acuity and/or metamorphopsia.

\section{Material and methods}

This retrospective study included consecutive symptomatic patients, who complained on reduction of visual acuity and/ or metamorphopsia, and confirmed by OCT examination (Carl Zeiss Meditec, Dublin, CA, USA, 2000) at the Hillel-Yaffe Medical Centre to have a LMH. Following visual acuity, slit-lamp and fundus examinations after pupillary dilation and OCT examination in each case with presumed macular pathology were carried out. It initially included as a rule the automatic 6-radial lines programme (5.9-mm length each) centred at the macula. To search for possible omitted findings, the line group programme was thereafter used to scan the macula at various focuses and scan angles. This is followed by scanning of the posterior pole, when the OCT sets centred on other locations, mainly the papillomacular bundle (PMB) site and the optic nerve head $(\mathrm{ONH})$. Ethics Committee approval was not required for this retrospective study.

The diagnostic prerequisites of an LMH were based on three OCT criteria, similar to those described previously: $^{10,15}$ (1) a break in the inner fovea, (2) an irregular foveal contour, and (3) intact foveal photoreceptors. As the floor of the LMH is commonly irregular, ${ }^{10}$ the central foveal thickness was manually measured using OCT callipers at the thinnest point between the inner irregular foveal floor and the foveal base (next to the retinal pigment epithelium layer). For the control group, our earlier reported data were used, ${ }^{14}$ in which the mean foveal thickness of 10 age-matched healthy patients was $168 \pm 17 \mu \mathrm{m}$ (range, 141-189). This is similar to other previously reported data. ${ }^{16,17}$

Cystoid spaces at the foveal region were defined as cystoid-like cavities that appeared in various shapes like round or oval hyporeflective areas with hyperreflective septa separating the cystoid-like cavities. When the cystoid spaces were abundant or large enough to occupy a part of the foveal tissue, the condition was defined as cystoid foveal oedema (CFE). An intraretinal split denoted the separation of the inner from the outer foveal retinal layers. Excluded were eyes with old or recent uveitis and eyes that had previously undergone vitreo-retinal surgery.

\section{Results}

A total of 22 eyes of 20 consecutive symptomatic patients (12 men and 8 women; mean age, 68 years; range, 22-94), each with $\mathrm{LMH}$, were included in the study. Patient characteristics and the OCT findings are presented in Table 1. Minimal foveal thickness ranged between
51-149 $\mu \mathrm{m}$ (mean, 93.6 $\pm 29.2 \mu \mathrm{m}$ ). Excluded were eyes with LMH that was related to chronic uveitis $(n=1)$ and following vitreoretinal surgery $(n=1)$. In the control normal eyes, no cystoid spaces were detected at the foveal tissue.

In 21 of the 22 eyes (95\%), in comparison with the normal controls, accumulation of cystoid spaced at the residual fovea in various sizes, manifesting in each as CFE (Figure 1a-d), was detected. BCVA of the 21 eyes ranged between $6 / 9$ and $6 / 120$, and in the remaining eye without detectable cystoid spaced at the fovea, it was $6 / 24$, following branch retinal vein occlusion and argon laser treatment to the affected quadrant (Figure 2). The reduced visual acuity in the latter may be related to the ischaemic insult. The CFE was associated with adjacent CME in 11 (52\%) eyes (Figures $1 \mathrm{~b}$ and $\mathrm{c}$ and 2). An ERM was detected in 16 eyes ( $73 \%$; Figure $1 \mathrm{~b}$ and d). All detected ERMs were of the focally adherent type or globally adherent ERMs with typical associated findings as described previously, that is, a visible membrane tuft or edge, or a difference in optical reflectivity between the membrane and retina. ${ }^{7}$ In one eye (Figure 1d), the torn inner foveal layer was attached to a partially adherent ERM. An intraretinal split at the foveal wall was apparent in 18 eyes (82\%; Figures $1 b-d$ and 2).

\section{Discussion}

Cystoid spaces and oedema (CFE) at the residual foveal tissue were found in 21 (95.4\%) of the 22 eyes with LMH. These abnormalities may partially explain a reduced visual acuity and/or metamorphopsia. Haouchine et $a l^{10}$ reported irregularities that were often present at the foveal base of the $\mathrm{LMH}$, and Hirakawa et al ${ }^{12}$ have suggested that such irregularities may be the reason for the relatively poor visual acuity. We assume that these irregularities could actually, in part, represent cystoid spaces and oedema at the fovea. However, Wilkin et al ${ }^{13}$ suggest that low visual acuity in eyes with LMHs could be related to the existence of an intraretinal split.

In contrast with reported BCVA of patients with $\mathrm{LMH}$ before the OCT era, which typically ranged between $20 / 20$ and $20 / 80,{ }^{3}$ BCVA in OCT-based studies ranged between 20/100 and counting fingers at 8 feet in one-third of the patients. ${ }^{11,13}$ This difference in visual acuity before and at the OCT era may partly be explained by the fact that the OCT enables diagnosis of LMH even if minute foveal tissue remains. Perhaps this may show that clinical evaluation of deep LMHs, without the aid of OCT, associated with poor visual acuity could mistakenly be diagnosed as full-thickness holes. Further information on the LMH subject in the OCT era is needed. 
Table 1 Patients' characteristics and optical coherence tomography findings

\begin{tabular}{|c|c|c|c|c|c|c|c|}
\hline Patient & Age & $\begin{array}{l}\text { Gender } \\
(M / F)\end{array}$ & $\begin{array}{l}\text { Best-corrected } \\
\text { visual acuity }\end{array}$ & $\begin{array}{c}\text { Minimal foveal } \\
\text { thickness (microns) }\end{array}$ & $\begin{array}{l}\text { Epiretinal } \\
\text { membrane }\end{array}$ & $\begin{array}{c}\text { Cystoid foveal } \\
\text { oedema }\end{array}$ & $\begin{array}{c}\text { Intraretinal } \\
\text { split }\end{array}$ \\
\hline 1 & 61 & M & $6 / 18$ & 113 & Yes & Yes & No \\
\hline 2 & 63 & $\mathrm{~F}$ & $6 / 9$ & 108 & Yes & Yes & Yes \\
\hline 3 & 67 & M & $6 / 12$ & 107 & Yes & Yes & Yes \\
\hline 4 & 76 & F & $6 / 12$ & 83 & Yes & Yes & Yes \\
\hline 5 & 63 & F & $6 / 9$ & 104 & Yes & Yes & Yes \\
\hline 6 & 63 & F & $6 / 36$ & 84 & No & Yes & Yes \\
\hline 7 & 94 & F & $6 / 12$ & 98 & No & Yes & Yes \\
\hline 8 & 68 & M & $6 / 36$ & 70 & No & Yes & Yes \\
\hline 9 & 69 & M & $6 / 12$ & 132 & No & Yes & Yes \\
\hline 10 & 70 & M & $6 / 24$ & 51 & Yes & Yes & Yes \\
\hline 11 & 66 & M & $6 / 120$ & 53 & Yes & Yes & Yes \\
\hline 12 & 22 & $\mathrm{~F}$ & $6 / 9$ & 116 & Yes & Yes & Yes \\
\hline 13 & 89 & $\mathrm{~F}$ & $6 / 12$ & 90 & Yes & Yes & Yes \\
\hline $14 \mathrm{RE}$ & 68 & $\mathrm{M}$ & $6 / 12$ & 51 & Yes & Yes & No \\
\hline $14 \mathrm{LE}$ & & & $6 / 24$ & 55 & Yes & Yes & Yes \\
\hline 15 & 74 & M & $6 / 9$ & 133 & Yes & Yes & Yes \\
\hline $16 \mathrm{RE}$ & 75 & M & $6 / 18$ & 82 & Yes & Yes & No \\
\hline $16 \mathrm{LE}$ & & & $6 / 9$ & 133 & Yes & Yes & No \\
\hline 17 & 67 & F & $6 / 12$ & 149 & No & Yes & No \\
\hline 18 & 80 & M & $6 / 24$ & 67 & No & No & Yes \\
\hline 19 & 72 & $\mathrm{~F}$ & $6 / 9$ & 75 & Yes & Yes & Yes \\
\hline 20 & 62 & $\mathrm{M}$ & $6 / 9$ & 106 & Yes & Yes & Yes \\
\hline Mean & 68.5 & & & 93.6 & & & \\
\hline SD & 14.0 & & & 29.2 & & & \\
\hline
\end{tabular}

$\mathrm{F}=$ female; $\mathrm{LE}=$ left eye; $\mathrm{M}=$ male; $\mathrm{RE}=$ right eye.

Similar to earlier studies, ${ }^{10,15}$ the fovea in this study was found thinner than normal in most eyes. However, 'foveal thickness' of the LMH refers to its thinnest part. But foveal thickness at other sites may be normal, falsely normal, or even above normal, as cystoid spaces and CFE are an unavoidable part of the measurement. Accordingly, Witkin et $a l^{13}$ have proposed to broaden the definition of $\mathrm{LMH}$, claiming that an eye with thick fovea should also be designated as LMH provided that it has the typical aforementioned LMH diagnostic criteria.

The presence of CFE in eyes with LMHs may suggest in theory a potential of dynamic properties. These may include either enlargement and/or coalescent of the cystoid spaces or their rupture with subsequent tissue thinning, and a potential of reversibility following surgery. Several OCT studies on LMHs seem to suggest such dynamic properties: (a) two OCT studies report the transition of LMH to a full-thickness macular hole ${ }^{9,13}$ and (b) improved visual acuity was achieved following PPV in most of the eyes in which ILM peeling was performed. ${ }^{11-13}$ Garretson et al ${ }^{11}$ reported the largest series of 27 patients with LMH, who underwent PPV and ILM peeling. Surgery was beneficial in 25 (93\%) patients, with a mean gain of $>3$ Snellen lines of acuity. In concomitance, improved foveal appearance was detected by OCT in most patients.
An ERM was detected in our series in $73 \%(16 / 22)$ of eyes. It is noteworthy that in one eye (Figure 1d), the LMH seems to be secondary to a tangential traction and a tear of the inner fovea by a partially adherent ERM. To the best of our knowledge, this is a relatively unrecognized phenomenon. Guyer et $a l^{18}$ described ERM in $50 \%(6 / 12)$ of eyes with LMHs, and suggested that ERM tangential traction could play a role in the pathogenesis of LMH. Mori et $a l^{19}$ reported that $68.5 \%$ (48/70 eyes) of ERMs were globally adherent to the retina, and therefore their detection by OCT could often be omitted. By using an ultra-high resolution OCT ( $3 \mu \mathrm{m}$ resolution), Witkin et al ${ }^{13}$ detected ERMs in $89 \%$ of eyes with LMHs $(n=19)$. Therefore, it may be possible that more ERMs, mainly of the globally adherent type, would have been detected using a higher resolution OCT.

Despite the common OCT findings of cystoid spaces or CFE in symptomatic LMHs in the present series, only two cases of LMH transition to a full-thickness hole have been reported in the OCT era. In comparison with another macular abnormality associated with ERM, that is, macular pseudoholes, one-third $(9 / 27)$ of eyes showed an evolution into a full-thickness macular hole after 36 months of follow-up. ${ }^{20}$ Although speculative, it is possible that the relative infrequent transition of an $\mathrm{LMH}$ to full-thickness hole, even under OCT evaluation, may 

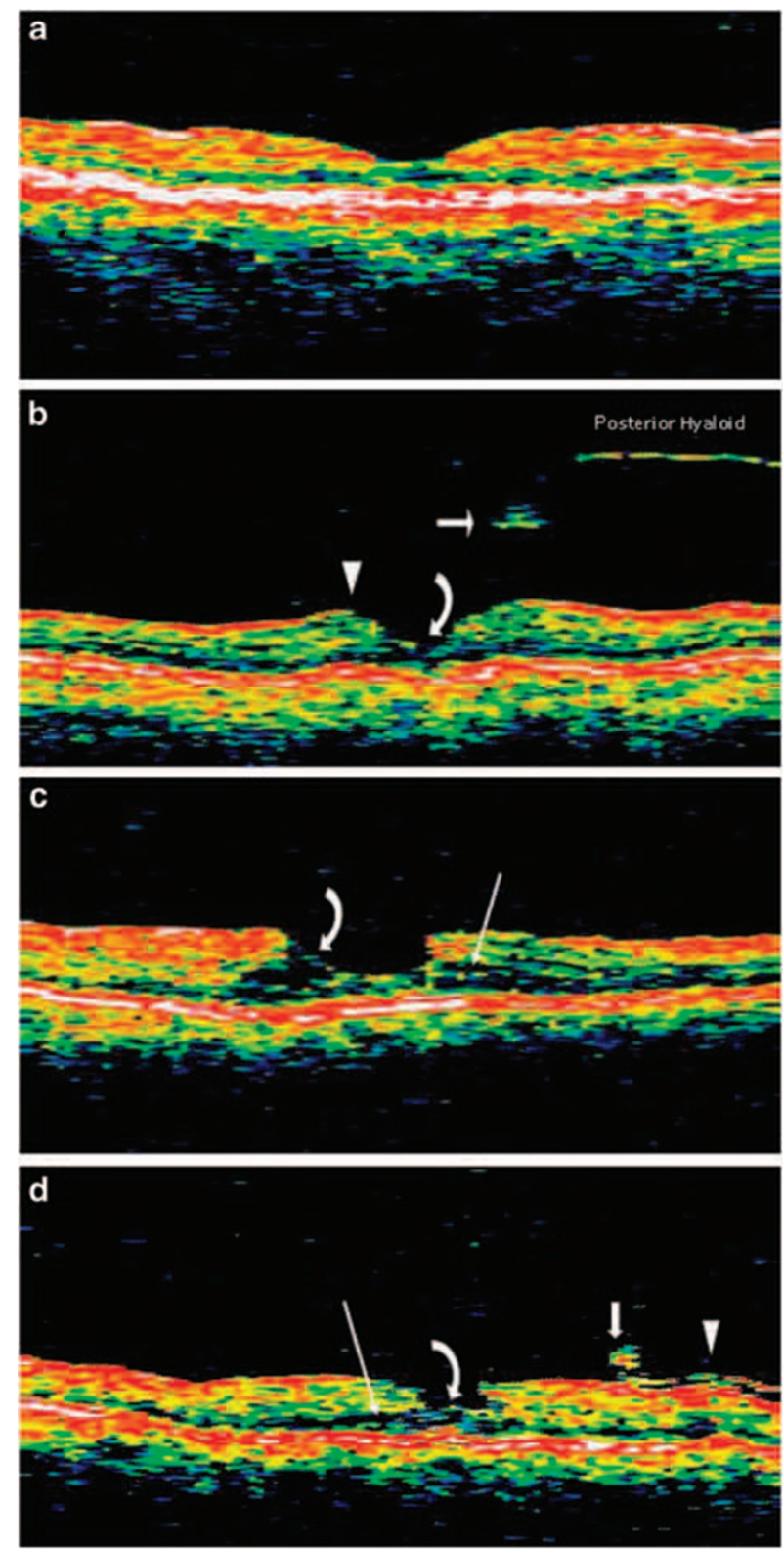

Figure 1 (a-d) Lamellar macular holes (LMHs) with cystoid foveal oedema. (a) Optical coherence tomography (OCT) of a normal fovea. The thinnest foveal tissue is $173 \mu \mathrm{m}$. The foveal tissue is free of cystoid spaces. (b-d) OCT of an LMH in each of three symptomatic patients. Torn inner foveal tissues, presenting either as a pseudo-operculum (b, short arrow) or attached to a partially adherent epiretinal membrane are detected $(\mathrm{d}$, short arrow). An epiretinal membrane is detected in panels $b$ and $d$ (triangular arrows). An intraretinal split, which denoted separation of the inner from the outer foveal retinal layers, is apparent in panels $\mathrm{c}$ and $\mathrm{d}$ (long arrows). The residual fovea base in each eye is oedematous, containing cystoid spaces of various sizes (curved arrows). The thinnest sites at the three foveal tissues ranged between 83 and $116 \mu \mathrm{m}$.

be related to a lesser tangential traction in LMHs than in pseudoholes, as the ILM (and underlying tissue) is already torn in LMH. This could explain slower

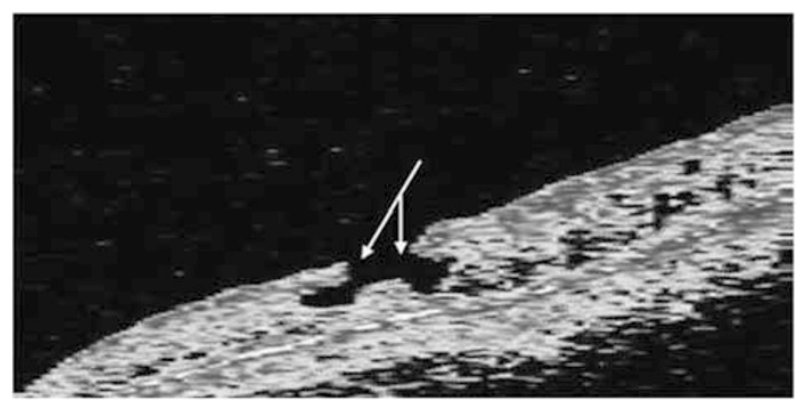

Figure 2 A lamellar macular hole (LMH) without foveal cystoid changes. Optical coherence tomography (OCT) of a $\mathrm{LMH}$ following branch retinal vein occlusion. The residual foveal tissue is free of cystoid spaces or oedema. Cystoid macular oedema is adjoining the LMH. An intraretinal split is apparent (arrows). The thinnest foveal tissue (as measured in another scan) is $84 \mu \mathrm{m}$.

progression or halting of the cystoid process at the fovea. However, if the oedematous process at the LMH continues to progress, it might indicate the ongoing persistent tangential forces. PPV associated with ILM peeling, ${ }^{11-13}$ which is naturally broader in area than that of the original LMH opening, may allow release of the tangential tension with an improvement of visual acuity or metamorphopsia in most cases.

Limitations of this study relate to a lack of follow-up, which could prove the progression, and the relatively small series. However, the study points to changes that might exist at the residual foveal tissue of symptomatic LMH that may explain poor visual acuity and/or metamorphopsia. Further studies are required to ascertain these findings and their clinical relevance.

\section{References}

1 Gass JD. Idiopathic senile macular hole. Its early stages and pathogenesis. Arch Ophthalmol 1988; 106: 629-639.

2 Gass JD. Lamellar macular hole: A complication of cystoid macular edema after cataract extraction. Arch Ophthalmol 1967; 94: 793-800.

3 Schachat A, Murphy R. Macular hole. In: Stephen J Ryan, Andrew P Schachat, Robert P Murphy (eds). Medical Retina. Mosby: Baltimore, MD, 1994; 1173-1175, 1169-1170.

4 Karatas M, Ramirez JA, Ophir A. Diabetic vitreopapillary traction and macular oedema. Eye 2005; 19: 676-682.

5 Puliafito C, Hee M, Schuman J, Fujimoto JG (eds). Macular hole and vitreomacular traction. In Optical Coherence Tomography of Macular Diseases. SLACK Incorporated: Thorofare NJ, 1995; 39-83.

6 Gaudric A, Haouchine B, Massin P, Paques M, Blain P, Erginay A. Macular hole formation: new data provided by optical coherence tomography. Arch Ophthalmol 1999; 117: 744-751.

7 Wilkins JR, Puliafito CA, Hee MR, Duker JS, Reichel E, Coker JG et al. Characterization of epiretinal membranes 
using optical coherence tomography. Ophthalmology 1996; 103: 2142-2151.

8 Hee M, Puliafito C, Wong C, Duker JS, Reichel E, Schuman JS et al. Optical coherence tomography of macular holes. Ophthalmology 1995; 120: 748-756.

9 Takahashi H, Kishi S. Tomographic features of lamellar macular hole formation and lamellar hole that progressed to a full thickness macular hole. Am J Ophthalmol 2000; 130: 677-679.

10 Haouchine B, Massin P, Tadayoni R, Erginay A, Gaudric A. Diagnosis of macular pseudohole and lamellar macular holes by optical coherence tomography. Am J Ophthalmol 2004; 138: 732-739.

11 Garretson BR, Pollack JS, Ruby AJ, Drenser KA, Williams GA, Sarrafizadeh R. Vitrectomy for a symptomatic lamellar macular hole. Ophthalmology 2007; 115(5): 884-886.e1.

12 Hirakawa M, Uemura A, Nakano T, Sakamoto T. Pars plana vitrectomy with gas tamponade for lamellar macular holes. Am J Ophthalmol 2005; 140: 1154-1155.

13 Witkin AJ, Ko TH, Fujimoto JG, Schuman JS, Baumal CR, Rogers $\mathrm{AH}$ et al. Redefining lamellar holes and the vitreomacular interface: an ultrahigh-resolution optical coherence tomography study. Ophthalmology 2006; 113: 388-397.
14 Ramirez JA, Karatas M, Fatum S, Halpert M, Ophir A Lamellar macular hole and continuous vitreofoveal adherence. Harefuah 2005; 144: 794-797.

15 Koizumi H, Spaide RF, Fisher YL, Freund KB, Klancnik Jr JM, Yannuzzi LA. Three-Dimensional evaluation of vitreomacular traction and epiretinal membrane using spectral domain optical coherence tomography. Am J Ophthalmol 2008; 145: 509-517.

16 Konno S, Akiba J, Yoshida A. Retinal thickness measurements with optical coherence tomography and the scanning retinal thickness analyzer. Retina 2001; 21: 57-61.

17 Massin P, Erginay A, Haouchine B, Mehidi AB, Paques M, Gaudric A. Retinal thickness in healthy and diabetic subjects measured using optical coherence tomography mapping software. Eur J Ophthalmol 2002; 12: 102-108.

18 Guyer DR, Green WR, de Bustros S, Fine SL. Histopathologic features of idiopathic macular holes and cysts. Ophthalmology 1990; 97: 1045-1051.

19 Mori K, Gehlbach PL, Sano A, Deguchi T, Yoneya S. Comparison of epiretinal membranes of differing pathogenesis using optical coherence tomography. Retina 2004; 24: 57-62.

20 Varano M, Scassa C, Capaldo N, Sciamanna M, Parisi V. Development of macular pseudoholes: a 36-month period of follow-up. Retina 2002; 22: 435-442. 